Disponível em

http://www.anpad.org.br/rac

RAC, Rio de Janeiro, v. 16, n. 1, art. 8, pp. 137-156, Jan./Fev. 2012

$(\mathrm{oc})$ EY-No

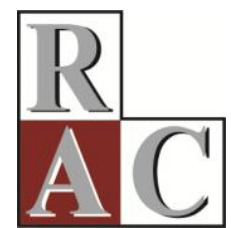

\title{
A Influência dos Valores Organizacionais no Desempenho de Agências Bancárias
}

The Influence of Organizational Values on Bank Branch Performance

Wagner Fabiano de Melo *

E-mail: melo.wagner@gmail.com Universidade Presbiteriana Mackenzie

São Paulo, SP, Brasil.

Silvia Marcia Russi De Domenico

E-mail: silviarussi@mackenzie.br PPGA/Universidade Presbiteriana Mackenzie São Paulo, SP, Brasil.

\footnotetext{
* Endereço: Wagner Fabiano de Melo
}

Rua Uruguai, 130, Osasco/SP, 06033-290.

Copyright (C) 2012 RAC. Todos os direitos, até mesmo de tradução, são reservados. É permitido citar parte de artigos sem autorização prévia, desde que seja identificada a fonte. 


\title{
Resumo
}

Este artigo objetivou verificar a influência dos valores organizacionais de agências bancárias no desempenho destas unidades. A pesquisa foi desenvolvida em uma instituição bancária pública. O Inventário de Perfis de Valores Organizacionais (IPVO) foi adaptado para a mensuração dos valores organizacionais das agências. O desempenho de cada agência foi medido de forma objetiva, pelo percentual de metas integralmente realizadas no ano de 2009. A amostra é do tipo não probabilística e composta por 271 agências, cujos dados acerca dos valores organizacionais foram proporcionados por 720 respondentes. A análise dos dados revelou que os valores organizacionais das agências se estruturam em quatro fatores: respeito aos stakeholders, diversão para os empregados, atuação competente e prestígio. Prestígio está positivamente correlacionado com o desempenho e o respeito aos stakeholders e a diversão para os empregados estão inversamente correlacionados com a variável dependente. A análise de regressão múltipla resultou em um modelo que explica 9,5\% da variância no desempenho e composto por dois fatores como variáveis preditoras que influenciam positivamente o desempenho: prestígio e atuação competente. Os resultados mostraram que os valores organizacionais são uma das variáveis que podem impactar no desempenho de agências bancárias.

Palavras-chave: valores organizacionais; desempenho organizacional; agência bancária.

\begin{abstract}
This paper aimed to investigate the influence organizational values at bank branches have on bank branch performance. The research was undertaken at branches of a Brazilian publicly held bank. The questionnaire called Inventário de Perfis de Valores Organizacionais (IPVO, or Inventory of Organizational Values Profiles) was adapted to measure the organizational values of bank branches. Bank branch performance was measured objectively, using the percentage of goals accomplished during the year 2009. The sample is non-probabilistic and is formed by 271 bank branches and the data about the organizational values of bank branches was provided by 720 respondents. Data analysis revealed that the organizational values of bank branches are organized into four factors: respect for stakeholders, employee entertainment, competent performance, and prestige. Prestige is positively correlated with bank branch performance, and respect for stakeholders and employee entertainment are negatively correlated with the dependent variable. The multiple regression analysis yielded an equation that accounts for $9.5 \%$ of the variance in performance and contains two factors as independent variables which positively influence bank branch performance: prestige and competent performance. The results showed that organizational values are one of the variables that can impact bank branch performance.
\end{abstract}

Key words: organizational values; organizational performance; bank branch. 


\section{Introdução}

O desempenho organizacional é, de acordo com Venkatraman e Ramanujam (1986), um tema de grande importância para gestores e acadêmicos de diversas áreas da Administração. Combs, Crook e Shook (2005) acrescentam que o desempenho é provavelmente o construto mais importante para a administração estratégica.

Cameron (1981) identifica o desenvolvimento de quatro abordagens teóricas para a definição de desempenho organizacional. A primeira surgiu na década de 1950 e considera que o desempenho está associado à formulação e alcance de metas financeiras. Por volta dos anos 1970, duas novas perspectivas foram introduzidas: adaptação ao meio ambiente, que representa a obtenção, por uma organização, dos recursos do ambiente externo necessários para a sua sobrevivência e eficiência de estruturas e processos, na qual o desempenho é o nível de eficiência do funcionamento da organização. Na última abordagem, surgida na década de 1980 e intitulada satisfação dos stakeholders, o desempenho é o grau em que as necessidades e expectativas de diferentes grupos de interesse são satisfeitas pela empresa.

Entre as diversas variáveis que podem afetar direta ou indiretamente o desempenho de uma organização estão os valores organizacionais, definidos por Tamayo e Gondim (1996) como "princípios ou crenças, organizados hierarquicamente, relativos a tipos de estrutura ou a modelos de comportamento desejáveis que orientam a vida da empresa e estão a serviço de interesses individuais, coletivos ou mistos" (p. 63). Verifica-se, nesta definição, a importância que estes valores possuem, ao serem orientadores da vida organizacional. Para outros autores, os valores organizacionais indicam os modos de resolver problemas e são um dos fundamentos das práticas de uma organização e, consequentemente, dos resultados obtidos (Denison, 1997). Não obstante, nota-se uma carência de pesquisas brasileiras dedicadas ao exame da relação entre desempenho e valores organizacionais, como se verá a seguir.

Ferreira, Fernandes e Silva (2009) realizaram um balanço da produção nacional sobre valores organizacionais, publicada entre 2000 e 2008, nos principais periódicos das áreas de Administração e Psicologia. As autoras localizaram 58 estudos nos quais os valores organizacionais foram investigados como variáveis únicas, antecedentes ou consequentes de diversos construtos, entre os quais não estava presente o desempenho organizacional. Buscas foram realizadas nas mesmas publicações examinadas por Ferreira et al. (2009), para o período de janeiro de 2009 a dezembro de 2010. Do mesmo modo que as autoras, foram utilizados os seguintes termos nas consultas: valores, cultura, cultural, valores organizacionais e cultura organizacional. Quatro trabalhos foram localizados e nenhum deles pesquisou o impacto dos valores organizacionais no desempenho. Adicionalmente, foram realizadas consultas na base de dados da Biblioteca Digital de Teses e Dissertações (BDTD), no mês de janeiro de 2011, com a procura da expressão valores organizacionais no resumo dos trabalhos. Foram encontradas 31 pesquisas que estudaram os valores organizacionais, das quais nenhuma investigou a relação entre estes valores e desempenho. Também no mês de janeiro de 2011, foram identificados os artigos apresentados nas edições de 1997 a 2010 do Enanpad, que abordaram os valores organizacionais, buscando-se a palavra valores nos títulos dos documentos. Encontraram-se 34 trabalhos; nenhum explorou a influência dos valores organizacionais no desempenho.

Todavia há estudos realizados no exterior, tais como Lytle (1994) e Voss, Cable e Voss (2000), que examinaram o impacto direto ou indireto dos valores organizacionais no desempenho, sem se utilizar, contudo, de uma teoria sobre a estrutura dos valores para a análise da relação entre os construtos. Conforme Rohan (2000), a falta de uma teoria acerca da estrutura dos valores impede compreender as consequências que a priorização de um valor acarreta para os demais e a influência do conjunto dos valores em outra variável.

Neste sentido, identifica-se a necessidade, pelo menos no Brasil, de investigar a influência dos valores organizacionais no desempenho, com base em uma teoria de valores. A presente pesquisa dedica-se a este objetivo. $\mathrm{O}$ estudo foi realizado em agências bancárias de uma instituição financeira 
pública, referenciada neste artigo como Banco, pelos seguintes motivos: a organização possui um grande número de agências distribuídas pelo país e utiliza um modelo de avaliação de resultados que permite a comparação do desempenho entre elas. Adicionalmente, ao pertencerem à mesma instituição bancária, estas agências operam sob as mesmas políticas e oferecem os mesmos produtos e serviços, o que limita o efeito destas variáveis no desempenho, aspecto também ressaltado por Bartel (2004), ao investigar a relação entre práticas de gestão de pessoas e desempenho de 160 agências de um banco canadense.

\section{Valores Organizacionais}

Agle e Caldwell (1999) afirmam que, apesar de o estudo sobre valores organizacionais ser realizado há várias décadas, o crescimento no interesse pelo tema ocorreu com o surgimento do termo cultura organizacional, na década de 1970. Alguns conceitos e modelos de cultura organizacional fazem referência aos valores.

Para Cameron e Quinn (1999), por exemplo, a cultura organizacional "refere-se aos valores aceitos tacitamente, pressupostos implícitos, expectativas, memórias coletivas e definições presentes em uma organização" (p. 14, tradução nossa). Entre as funções dos valores estão estas: comunicar um senso de identidade aos empregados; proporcionar orientações geralmente não escritas sobre como agir na organização; e aumentar a estabilidade do sistema social. Denison (1997) afirma que a cultura "se refere aos valores, crenças e princípios subjacentes, que servem como fundamento do sistema de gerenciamento organizacional" (p. 2, tradução nossa). Estes elementos representam, para os membros da organização, soluções que funcionaram adequadamente no passado e que funcionarão novamente no futuro.

Hofstede (2003) conceitua cultura como "a programação coletiva da mente que distingue os membros de uma organização dos de outra" (p. 210). Para o autor, as manifestações da cultura ocorrem em diferentes níveis de profundidade. Os símbolos são as palavras, figuras e objetos e representam a camada mais superficial. Em nível um pouco mais profundo, estão os heróis, que são pessoas valorizadas e que servem de modelos de comportamento e os rituais, compostos por atividades coletivas de grande relevância. Estes três elementos representam as práticas, visíveis a um observador externo. O núcleo da cultura é composto pelos valores, que Hofstede (2003) define como "uma tendência para se preferir certo estado de coisas face a outro" (p. 23).

Os valores organizacionais, contudo, não são apenas pesquisados como elementos na compreensão da cultura das organizações. Esta linha de estudo, como apontam Mendes e Tamayo (2001), desenvolve "modelos para identificar a cultura organizacional, mas não especificamente um modelo de estudo dos valores organizacionais" (p. 39). Um segundo campo de pesquisa investiga estes valores como um tema específico (Mendes \& Tamayo, 2001), explorando, por exemplo, o seu impacto no comprometimento (Tamayo, 2005a). O presente estudo enquadra-se nesta última linha de investigação.

Tamayo e Gondim (1996) ressaltam alguns aspectos dos valores organizacionais que contribuem para a sua compreensão. (a) Cognitivo: estes valores indicam as respostas, resultantes de um aprendizado cumulativo, a serem dadas pelos membros aos problemas e questões organizacionais e representam o modo de funcionamento da organização. (b) Motivacional: os valores organizacionais atuam como motivadores do comportamento, determinando a persistência dos membros em alcançar as metas da organização (Tamayo \& Borges, 2006). (c) Hierarquia: cada valor organizacional é ordenado por sua importância relativa aos demais, formando um sistema de valores hierarquicamente organizado, que indica preferências por determinados objetivos e comportamentos.

Segundo Tamayo (2007), há três estratégias para identificar os valores de uma organização. A primeira baseia-se na média dos valores individuais dos empregados. Ela é criticada, pois os valores 
organizacionais são diferentes dos pessoais (Tamayo \& Gondim, 1996). A segunda identifica os valores esposados, que não necessariamente são praticados (Oliveira \& Tamayo, 2004). A última, por sua vez, faz uso da percepção dos empregados sobre os valores praticados na organização. De acordo com Tamayo e Borges (2006), esta estratégia é a mais rica por fundamentar-se no que ocorre no cotidiano da empresa. Acrescenta-se que os valores organizacionais, percebidos como praticados, exercem influência no comportamento do funcionário (Tamayo, Mendes, \& Paz, 2000). Deste modo, esta última abordagem foi a adotada na presente pesquisa.

Três escalas foram criadas no Brasil para a mensuração dos valores organizacionais, a partir da percepção dos trabalhadores: a Escala de Valores Organizacionais (EVO) (Tamayo \& Gondim, 1996); o Inventário de Valores Organizacionais (IVO) (Tamayo et al., 2000); e o Inventário de Perfis de Valores Organizacionais (IPVO) (Oliveira \& Tamayo, 2004).

A EVO foi construída com base exclusivamente empírica (Tamayo, 2007). Para a concepção do IVO, além de dados empíricos, os autores basearam-se na teoria de valores culturais de Schwartz (1999) (Tamayo et al., 2000). Já o IPVO foi elaborado a partir de dados empíricos e da teoria de valores pessoais ou básicos de Schwartz (1992), fundamentando-se no princípio de que os valores pessoais e os organizacionais possuem uma estrutura similar (Oliveira \& Tamayo, 2004). Entre as 31 teses e dissertações publicadas na BDTD, localizadas na pesquisa bibliográfica, mencionada na introdução do artigo, 25 aplicaram questionários para a mensuração dos valores organizacionais e, destas, 13 adotaram o IPVO. Dos 34 artigos apresentados no Enanpad, 18 pesquisaram quantitativamente os valores organizacionais, dos quais 11 utilizaram este inventário. Portanto, por ter sido adotado na maioria dos estudos citados, o IPVO foi escolhido no presente estudo; com isto a teoria de valores pessoais de Schwartz (1992) é abordada em seguida.

Schwartz (2006) considera os valores como "metas desejáveis e transituacionais, que variam em importância, servem como princípios na vida de uma pessoa ou de outra entidade social" (p. 57) e desenvolve uma teoria de valores pessoais, segundo a qual todos os indivíduos, independentemente da cultura, reconhecem a existência de dez tipos de valor. Os tipos de valor, intitulados de tipos motivacionais por se basearem na motivação que expressam, são derivados de respostas que as pessoas produzem para três necessidades humanas básicas: biológicas; de interação social coordenada; e de sobrevivência e funcionamento dos grupos (Schwartz, 1992). A teoria foi testada empiricamente em diversas pesquisas transculturais realizadas desde 1988 em mais de 60 países (Schwartz, 2005a).

Os dez tipos motivacionais de valores propostos por Schwartz (1992, 2005a, 2006) são: (a) poder, definido pela busca de status social e controle sobre pessoas e recursos; (b) realização, que se expressa pelo alcance de sucesso mediante a demonstração de competência; (c) hedonismo, representado pela procura do prazer e gratificação sensual para si mesmo; (d) estimulação, cujas metas são a novidade e desafio na vida; (e) autodeterminação, caracterizado pelo pensamento e escolhas independentes; (f) universalismo, que enfatiza a compreensão e proteção do bem-estar das pessoas em geral e da natureza; ( $\mathrm{g}$ ) benevolência, cujo destaque é a preservação do bem-estar das pessoas mais próximas; (h) tradição, que acentua o respeito e a aceitação dos costumes; (i) conformidade, voltado à restrição de ações e impulsos que possam contrariar expectativas sociais; e (j) segurança, cuja ênfase é a harmonia e estabilidade da sociedade, das relações e de si mesmo.

Além de uma tipologia dos valores, Schwartz (1992, 2005a, 2006) apresenta uma estrutura que revela as relações entre os tipos motivacionais. O pressuposto para a identificação da estrutura, representada em um círculo (Figura 1), é a possibilidade de conflitos e compatibilidades entre as consequências da realização dos valores. Os tipos motivacionais adjacentes possuem motivações semelhantes e, portanto, são congruentes. Os tipos antagônicos emanam, em direções opostas, do centro da representação circular. 


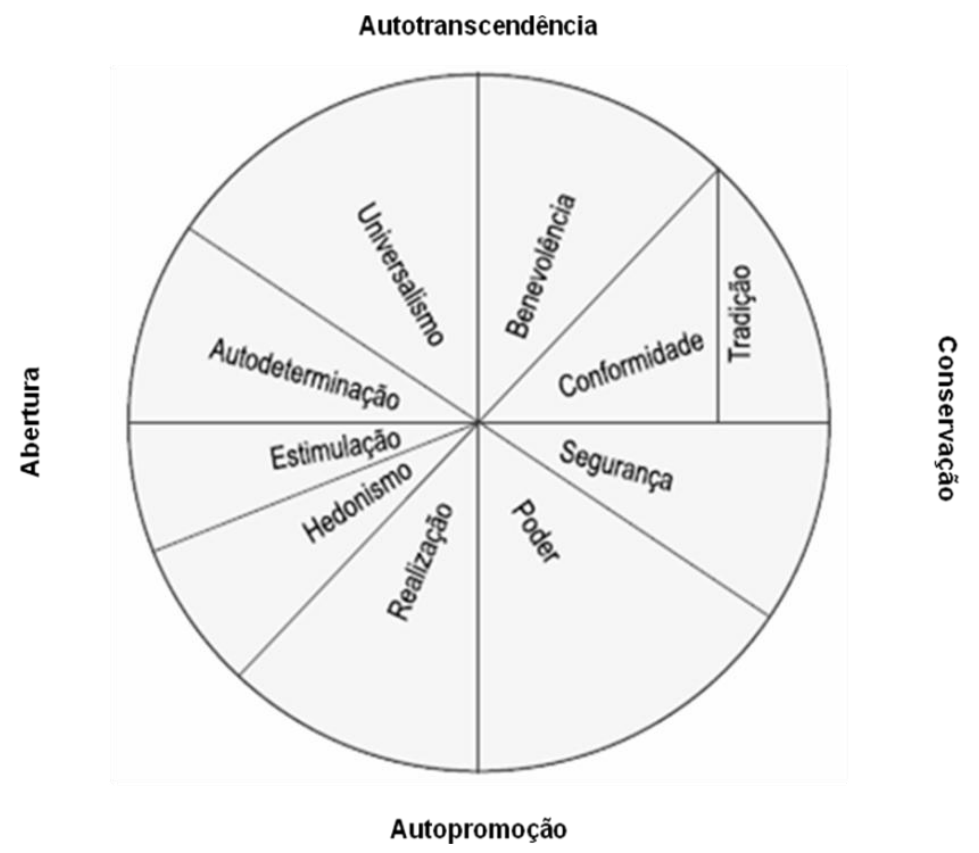

Figura 1. Estrutura dos Tipos Motivacionais de Valores.

Fonte: Schwartz, S. H. (2005a). Valores humanos básicos: seu contexto e estrutura intercultural (p. 30). In A. Tamayo \& J. B. Porto (Orgs.), Valores e comportamento nas organizações (pp. 21-55). Petrópolis: Vozes.

As oposições entre os tipos de valor podem ser resumidas em duas dimensões bipolares, como afirma Schwartz (2005a, 2006). Uma delas contrasta os polos: abertura à mudança e conservação. Reúne, de um lado, os valores voltados à independência (estimulação e autodeterminação); no outro polo, os valores que enfatizam a autorrepressão (segurança, conformidade e tradição). A segunda dimensão contrapõe os polos: autopromoção e autotranscendência. No primeiro, estão os valores relacionados com a busca de sucesso pessoal e domínio: poder e realização. Na outra extremidade, situam-se valores que se caracterizam pela ênfase no bem-estar dos outros: universalismo e benevolência. Os valores de hedonismo podem localizar-se no polo de abertura à mudança ou no de autopromoção.

O princípio de conflito e compatibilidade, contudo, não é o único possível para organizar a estrutura axiológica. Outra opção é baseada em quem tem os seus interesses atendidos pela realização dos valores (Schwartz, 1992, 2005a). Os tipos motivacionais que exprimem interesses dos indivíduos localizam-se à esquerda e na parte inferior do círculo: autodeterminação, estimulação, hedonismo, realização e poder. Tipos de valor que se encontram à direita do círculo expressam interesses da coletividade: benevolência, tradição e conformidade. Os valores de universalismo e segurança atendem a ambos os tipos de interesses.

Transpondo a teoria de valores pessoais para os valores organizacionais, Oliveira e Tamayo (2004) consideram que as pessoas e as organizações buscam valores estruturados semelhantemente. As justificativas para a similaridade entre as estruturas dos valores pessoais e organizacionais são: (a) ambos compartilham características gerais dos valores possuindo, por exemplo, componente motivacional; (b) as funções dos dois conjuntos de valores são parecidas, na medida em que os pessoais orientam a vida dos indivíduos e os organizacionais, a vida da organização; (c) os valores organizacionais podem ser originários dos valores pessoais dos fundadores e membros influentes na empresa; e (d) as pessoas procuram atingir metas fundamentais de sua existência, ao trabalhar nas organizações que, assim, devem ser um espaço para a realização destas metas (Oliveira \& Tamayo, 2004).

No processo de criação do IPVO, Oliveira e Tamayo (2004) desenvolveram itens, a partir da teoria de valores humanos, de observação e de dados da vida organizacional disponíveis na literatura, 
de forma a representar cada um dos dez tipos motivacionais de valores pessoais. Após validação por juízes e semântica, uma versão do instrumento composta por 120 assertivas foi aplicada em uma amostra de 833 empregados, de organizações públicas e privadas. A análise fatorial, realizada com o método de fatores comuns (opção Principal Axis Factoring [PAF]) e rotação oblíqua, revelou uma solução de 48 itens distribuídos em oito fatores, que correspondem a nove tipos motivacionais de valores pessoais (Tabela 1). O tipo motivacional segurança não foi representado por nenhum fator. Oliveira e Tamayo (2004) acreditam que esta ausência decorre de deficiências na formulação das assertivas.

Tabela 1

Fatores do IPVO, Metas dos Valores Organizacionais e Correspondências com os Tipos Motivacionais e Polos dos Valores Pessoais

\begin{tabular}{|c|c|c|c|}
\hline Fator & Metas dos valores organizacionais & Tipos motivacionais & Polos \\
\hline Autonomia & $\begin{array}{l}\text { Oferecer desafios e variedade no } \\
\text { trabalho, estimular a curiosidade, a } \\
\text { criatividade e a inovação }\end{array}$ & $\begin{array}{l}\text { Autodeterminação e } \\
\text { estimulação }\end{array}$ & Abertura à mudança \\
\hline Bem-estar & $\begin{array}{l}\text { Promover a satisfação, o bem-estar e a } \\
\text { qualidade de vida no trabalho }\end{array}$ & Hedonismo & $\begin{array}{l}\text { Abertura à mudança ou } \\
\text { autopromoção }\end{array}$ \\
\hline Realização & $\begin{array}{l}\text { Valorizar a competência e o sucesso } \\
\text { dos trabalhadores }\end{array}$ & Realização & Autopromoção \\
\hline Domínio & $\begin{array}{l}\text { Obter lucros, ser competitiva e } \\
\text { dominar o mercado }\end{array}$ & Poder & Autopromoção \\
\hline Prestígio & $\begin{array}{l}\text { Ter prestígio, ser conhecida e } \\
\text { admirada por todos e oferecer } \\
\text { produtos e serviços satisfatórios para } \\
\text { os clientes }\end{array}$ & Poder & Autopromoção \\
\hline Tradição & $\begin{array}{l}\text { Manter a tradição e respeitar os } \\
\text { costumes da organização }\end{array}$ & Tradição & Conservação \\
\hline Conformidade & $\begin{array}{l}\text { Promover a correção, a cortesia e as } \\
\text { boas maneiras no trabalho e o respeito } \\
\text { às normas da organização }\end{array}$ & Conformidade & Conservação \\
\hline $\begin{array}{l}\text { Preocupação } \\
\text { com a } \\
\text { coletividade }\end{array}$ & $\begin{array}{l}\text { Promover a justiça e a igualdade na } \\
\text { organização, bem como a tolerância, } \\
\text { sinceridade e honestidade }\end{array}$ & $\begin{array}{l}\text { Benevolência e } \\
\text { universalismo }\end{array}$ & Autotranscendência \\
\hline
\end{tabular}

Nota. Fonte: adaptado de Oliveira, A. F., \& Tamayo, A. (2004). Inventário de perfis de valores organizacionais (p. 137). Revista de Administração, 39(2), 129-140.

a Apesar de Oliveira e Tamayo (2004) considerarem que o fator bem-estar do empregado está posicionado no polo de abertura à mudança; o tipo motivacional que este fator representa, hedonismo, pode se situar no polo de abertura à mudança ou autopromoção, de acordo com Schwartz (2005b, 2006).

Para Oliveira e Tamayo (2004), os resultados obtidos com a validação do inventário sugerem que a estrutura dos valores organizacionais é semelhante a dos valores pessoais, o que foi verificado posteriormente no estudo realizado por Canova e Porto (2010). Assim, a dimensão abertura à mudança versus conservação da teoria de valores de Schwartz $(1992,2005 \mathrm{a}, 2006)$ é representada pelos valores organizacionais de autonomia e bem-estar, no primeiro polo, e tradição e conformidade, no polo oposto. A dimensão autopromoção versus autotranscendência, por sua vez, é retratada pelos valores domínio, prestígio e realização, que se situam no primeiro polo e pela preocupação com a coletividade, que está no segundo. 


\section{Hipótese}

Diversos autores discorrem sobre as funções dos valores organizacionais que indicam uma possível influência, indireta e direta, destes valores no desempenho. Tamayo e Gondim (1996) argumentam que os valores organizacionais são determinantes da rotina diária da empresa. Para Tamayo (2005b), a função destes valores é "criar condições favoráveis para a emergência e o desenvolvimento do bem-estar da organização e do trabalhador" (p. 201). Tamayo e Borges (2006) acrescentam que os valores da organização contribuem para a integração interna, "motivam a consecução de metas e objetivos" (p. 422) e "são imperativos para a eficácia organizacional" (p. 422). Conforme Tamayo (1998), estes valores "determinam ... a produtividade organizacional" (p. 58). Para Deal e Kennedy (2000), por sua vez, os valores são a essência da filosofia de sucesso de uma empresa.

Pesquisas demonstram que o desempenho de agências bancárias é influenciado por algumas práticas. Lytle (1994), por exemplo, verificou que ações que caracterizam orientações organizacionais de marketing e de serviço afetaram diversos indicadores de desempenho de 43 agências de um banco de varejo dos Estados Unidos. As práticas, por sua vez, se fundamentam em valores organizacionais (Denison, 1997), o que também foi identificado empiricamente por Lytle (1994), ao constatar, mediante análise de regressão, que as orientações de marketing e de serviço foram preditas por valores organizacionais das agências bancárias. Seis dimensões foram utilizadas pelo autor para a mensuração dos valores organizacionais: (a) ênfase externa versus interna: importância concedida pela organização na satisfação dos stakeholders externos ou no cumprimento de atividades internas; (b) foco nas tarefas versus foco no empregado: priorização da realização do trabalho ou do atendimento às necessidades dos trabalhadores; (c) segurança versus tolerância ao risco: ressalta o conservadorismo ou as mudanças constantes; (d) competitividade interna versus cooperação interna: salienta a disputa entre os colegas de trabalho por recursos escassos ou a ajuda mútua, voltada para os mesmos objetivos; (e) inovação versus estabilidade: representa a valorização da novidade ou relutância em adotar algo novo; e (f) atenção ao detalhe: ênfase empregada pela organização no detalhe, precisão e análise. As dimensões de valores que predisseram a orientação de serviço foram: foco no empregado e cooperação interna. A orientação de marketing, por sua vez, foi predita pelos valores que expressam uma ênfase externa.

Além dos estudos que mostram a influência indireta dos valores organizacionais, mediante as práticas, sobre o desempenho organizacional, há pesquisas que evidenciam o impacto direto desses valores no desempenho das empresas. Por exemplo, Gordon e DiTomaso (1992) identificaram que a predominância de valores categorizados como de adaptabilidade repercutiu em melhores índices de desempenho de onze organizações do ramo de seguros de vida. Em uma pesquisa realizada em 97 organizações de teatro profissionais sem fins lucrativos, Voss et al. (2000) identificaram cinco dimensões de valores organizacionais: (a) pró-social: congrega valores que enfatizam a dedicação em proporcionar acesso à arte para todas as pessoas de uma comunidade; (b) artística: representa a busca de um ideal estético e da criatividade artística intrínseca; (c) financeira: reúne valores que ressaltam a segurança e a estabilidade financeira; (d) marketing: destaca a procura pela satisfação dos clientes, oferecendo-lhes o entretenimento que desejam; e (e) realização: inclui valores que denotam um interesse profundo em alcançar um alto nível de excelência e o reconhecimento público quanto à qualidade do trabalho teatral. Estas cinco dimensões associaram-se ao volume de recursos financeiros obtidos pelas organizações teatrais, sendo que aquelas que mais valorizavam a dimensão de realização conseguiam a maior quantidade de recursos.

Lytle (1994) identificou diferenças entre as agências, nos graus de importância atribuídos aos valores organizacionais, o que, segundo o autor, revelou a existência de subculturas nestas unidades. Dissimilitudes nos sistemas de valores organizacionais das agências podem ser decorrentes da origem destes valores. Tamayo (2005a) afirma que os valores de uma organização podem ser derivados dos valores pessoais dos seus membros. Um grande número de empregados e gestores está distribuído pelas agências do Banco e diferenças nos sistemas de valores pessoais destes indivíduos podem resultar em possíveis dessemelhanças nas prioridades de valores destas unidades. Os valores organizacionais também são derivados das interações com exigências internas e externas (Oliveira \& 
Tamayo, 2004). Sendo as agências compostas por diferentes trabalhadores, pode-se esperar que exigências internas diversas interajam nestes locais. Por outro lado, estas unidades possuem clientes de variadas regiões do país, o que pode representar diferentes exigências externas que também contribuem para a formação de sistemas de valores organizacionais distintos.

A partir dos aportes teóricos e empíricos apresentados, a hipótese para a presente pesquisa é formulada conforme segue: os valores organizacionais das agências do Banco são preditores do desempenho destas agências.

\section{Metodologia}

A pesquisa realizada classifica-se como correlacional (Sampieri, Collado, \& Lucio, 2006), pois verificou a relação entre uma variável independente e uma dependente. A unidade de análise (Cavana, Delahaye, \& Sekaran, 2001) é a agência bancária, visto que os dados para a variável dependente (desempenho) se referem a estas unidades de negócio. A população do estudo eram todas as agências do Banco (quase 2.250 unidades). Foi adotada a amostragem não probabilística por conveniência (Cavana et al., 2001), devido às dificuldades para obtenção de dados de um conjunto de agências que representaria uma amostra probabilística.

Para a mensuração do desempenho das agências, dados foram obtidos do modelo de avaliação dos resultados das agências do Banco, que possui 28 indicadores distribuídos em seis perspectivas: (a) negócios pessoa física; (b) negócios pessoa jurídica; (c) clientes; (d) financeira; (e) pessoas; e (f) processos.

A perspectiva de negócios pessoa física é formada por dez indicadores que avaliam o desempenho obtido pela agência na concessão de empréstimos, captação de depósitos, vendas de cartões de crédito e outros serviços e produtos. A categoria de negócios pessoa jurídica se assemelha à anterior. Possui, entretanto, nove indicadores que refletem operações realizadas com empresas. Para a dimensão de clientes, duas medidas avaliam a prospecção e ativação de clientes, enquanto uma terceira mensura a quantidade de reclamações registradas por eles. A quarta perspectiva, intitulada financeira, verifica os resultados obtidos pela agência em três índices, dos quais a margem financeira bruta é um deles. Um indicador compõe a dimensão de pessoas: quantidade de horas de treinamento. A última perspectiva, chamada de processos, congrega duas medidas: conformidade às normas e risco de crédito. Os indicadores do modelo são compatíveis com medidas de desempenho de agências adotadas por outras instituições bancárias, como a pesquisada por Neves, Garcia e Morgan (2007).

Venkatraman e Ramanujam (1987) afirmam que os dados sobre o desempenho organizacional podem ser mensurados de modo objetivo ou percebido. No primeiro caso, são obtidos de relatórios contábeis ou outros sistemas de registros de dados factuais. O desempenho percebido, por sua vez, é baseado na avaliação subjetiva realizada por gestores, empregados ou especialistas de determinado setor. Assim, de acordo com esta tipologia, os indicadores de desempenho do modelo do Banco são classificados como objetivos.

O Banco estipula, para cada indicador e por agência, um valor que é a meta a ser alcançada em determinado período, geralmente um mês. O percentual de realização da meta é o nível de desempenho no indicador. A definição de metas aparenta compor um método de avaliação do desempenho de agências bancárias disseminado nas instituições financeiras, estrangeiras e nacionais, como pode ser observado em Lytle (1994) e Neves et al. (2007). Em decorrência do potencial de negócios do local onde estão situadas ou do porte das agências, há unidades que não possuem metas para alguns dos indicadores. Deste modo, para possibilitar a comparação do desempenho das agências, o Banco utiliza uma medida intitulada de desempenho geral e expressa em percentual: a quantidade de metas que tiveram um percentual de realização maior ou igual a $100 \%$ em um determinado período, dividida pelo total de metas atribuídas à agência para o período. 
$\mathrm{O}$ indicador de desempenho geral foi o índice utilizado na presente pesquisa para mensurar a variável dependente, pelos seguintes motivos: permite comparar o desempenho das agências e os dados do indicador foram os disponibilizados pelo Banco para a realização do estudo. Foram considerados os dados do período: de janeiro a dezembro de 2009.

Para a mensuração da variável independente foi utilizado o Inventário de Perfis de Valores Organizacionais (IPVO), desenvolvido para coletar respostas da percepção dos trabalhadores em relação aos valores organizacionais de uma empresa como um todo (Oliveira \& Tamayo, 2004). A presente pesquisa administrou esta escala para mensurar os valores organizacionais de cada agência do Banco e, para isto, existiu a necessidade de adaptá-la, o que foi feito em duas fases: primeiramente, o termo organização foi substituído pela palavra agência e, em seguida, o inventário com esta alteração foi submetido a um pré-teste colaborativo (Cooper \& Schindler, 2003), no qual os participantes foram cinco gerentes de agências diferentes. Estas pessoas avaliaram o questionário e apontaram, em uma entrevista, os itens não aplicáveis às agências do Banco. Optou-se por realizar o pré-teste com gestores, pois geralmente conhecem em profundidade as normas e o funcionamento das agências da instituição. A quantidade de participantes atendeu ao mínimo indicado por Hair, Babin, Money e Samouel (2006). O pré-teste revelou a necessidade de alterações adicionais em dois itens: 22 e 46 (expostos posteriormente na Tabela 3 ).

Para a sua aplicação, o instrumento de pesquisa foi hospedado em web site. Uma mensagem de convite para participação no estudo foi enviada em março de 2010 para cerca de $80 \%$ dos trabalhadores alocados nas agências do Banco. A web site foi acessada 3.742 vezes, em onze dias. Os acessos resultaram em 1.546 questionários preenchidos, o que representou uma taxa de participação de $4,8 \%$ em relação ao total de convidados. Além do IPVO, o instrumento era composto por questões sobre o perfil demográfico do respondente, dispostas no final da página eletrônica, conforme recomendação de Hair et al. (2006). Um participante somente poderia submeter um questionário, se todas as perguntas estivessem respondidas.

O banco de dados utilizado nas análises foi preparado em quatro passos, apresentados na Tabela 2. Na primeira etapa, foram excluídos os questionários cujo tempo de trabalho do participante na agência avaliada era menor do que três meses, prazo mínimo adotado por Oliveira e Tamayo (2004). Ainda neste passo, foram supressos os questionários cujo código informado de identificação da agência estava incorreto.

Entre as recomendações apresentadas por Schwartz (2005b) para tratamento dos dados obtidos com a aplicação do questionário Portrait Values Questionnaire (PVQ), versão com 21 itens, está a exclusão dos casos nos quais a mesma resposta foi fornecida para mais de 16 assertivas, o que representa 76\% do total de questões. Para Porto (2005), a exclusão dos respondentes que apresentaram baixa variabilidade nas respostas, ou viés de discriminação, também é aconselhável na mensuração dos valores organizacionais. Deste modo, no segundo passo, foram excluídos os questionários nos quais a mesma opção de resposta foi selecionada para 37 ou mais perguntas (quantidade que mais se aproximou de $76 \%$ dos itens do IPVO).

Tabela 2

Passos de Preparação do Banco de Dados

\begin{tabular}{clccc}
\hline Passo & \multicolumn{1}{c}{ Descrição } & Respondentes & Agências & $\begin{array}{c}\text { Respondentes por } \\
\text { agência }\end{array}$ \\
\hline Inicial & & 1.546 & 912 & 1,70 \\
\multirow{2}{*}{1} & (-) Tempo de agência menor que 3 meses & $(58)$ & $(23)$ & \\
& (-) Código incorreto de agência & $(73)$ & $(5)$ & \\
& Subtotal & 1.415 & 884 & 1,60 \\
\hline
\end{tabular}


Tabela 2 (continuação)

\begin{tabular}{clccc}
\hline Passo & \multicolumn{1}{c}{ Descrição } & Respondentes & Agências & $\begin{array}{c}\text { Respondentes por } \\
\text { agência }\end{array}$ \\
\hline 2 & (-) Casos com viés de discriminação & $(64)$ & $(24)$ & \\
& Subtotal & 1.351 & 860 & 1,57 \\
\multirow{2}{*}{3} & (-) Somente 1 empregado por agência & $(548)$ & $(548)$ & \\
& (-) Menos de 5\% dos empregados por agência & $(42)$ & $(21)$ & \\
& Subtotal & 761 & 291 & 2,62 \\
\multirow{2}{*}{4} & (-) Observações atípicas univariadas & $(12)$ & $(6)$ & \\
& (-) Observações atípicas multivariadas & $(29)$ & $(14)$ & \\
\hline
\end{tabular}

Nota. Os procedimentos dos passos 1 e 2 foram aplicados aos dados no nível individual, enquanto os procedimentos dos passos 3 e 4 foram aplicados para os dados agregados no nível de agências bancárias.

No terceiro estágio, foram eliminadas as agências cuja avaliação dos valores organizacionais foi realizada por apenas um funcionário. Este critério baseia-se na recomendação de Becker e Gerhart (1996) de utilizar avaliações de múltiplos respondentes, por organização ou unidade de negócio, na mensuração de construtos da área de recursos humanos, especialmente quando envolver subjetividade. Ainda nesta fase de preparação da amostra, foram retiradas as agências, cuja quantidade de respondentes era inferior a $5 \%$ dos funcionários, visto que este foi o percentual mínimo presente no estudo de Lytle (1994).

As observações atípicas univariadas e multivariadas (pela distância $D^{2}$ de Mahalanobis) (Hair, Anderson, Tatham, \& Black, 2005) foram examinadas no último passo. Estes métodos de detecção de casos extremos também foram adotados por Oliveira e Tamayo (2004). Verificou-se que as observações atípicas identificadas causavam grande diferença nos resultados da análise fatorial, gerando-se três fatores não discrimináveis e, assim, estas agências foram excluídas da amostra, seguindo-se a recomendação de Hair, Anderson, Tatham e Black (2005) de retirar os casos atípicos que prejudicam os resultados estatísticos.

Após a preparação do banco de dados, a amostra deste estudo ficou composta por 271 agências, situadas principalmente na região sul (39\%). Os dados dos valores organizacionais das agências foram fornecidos por 720 respondentes, cuja maior parte era do sexo masculino (55\%), possuía 46 anos ou mais (38\%), tinha curso superior completo ou pós-graduação (76\%) e não exercia função gerencial (76\%). Havia 520 participantes (72\%), cujo tempo de experiência na agência avaliada era de, no mínimo, dois anos. O percentual de trabalhadores, por agência, que preencheu o questionário variou de $5 \%$ a $40 \%$.

Os dados foram inicialmente submetidos à análise fatorial, pois com as modificações empreendidas no IPVO para a mensuração dos valores organizacionais das agências do Banco, existia a possibilidade de que a estrutura fatorial do construto fosse diferente da encontrada por Oliveira e Tamayo (2004). Estatística descritiva e regressão linear múltipla foram utilizadas em seguida. Em virtude de a agência ser a unidade de análise do presente estudo, os dados sobre os valores organizacionais coletados no nível individual foram agregados para o nível de agência, computando-se a média das respostas dos pesquisados que trabalhavam em uma mesma unidade para cada item do IPVO. Os dados agregados foram os utilizados nas análises a seguir. Recorreu-se ao software SPSS 15.0. 


\section{Apresentação, Análise e Interpretação dos Resultados}

Optou-se pela realização da análise fatorial exploratória (Hair et al., 2005), porquanto o IPVO sofreu alterações em relação à sua versão original. A avaliação das exigências estatísticas para a extração fatorial (Hair et al., 2005; Pett, Lackey, \& Sullivan, 2003), revelou o atendimento da maioria das suposições: variáveis do tipo métricas; amostra com, no mínimo, 5 observações por variável; bom número de correlações estatisticamente significativas entre as variáveis e que se situam entre 0,30 e 0,80; significância menor do que 0,05 no teste Bartlett de esfericidade (o resultado foi 0,000); e medida de adequação da amostra (MSA), avaliada para a matriz de correlação como um todo e para cada variável, acima de 0,50 (o resultado no teste KMO foi de 0,955 e, para as variáveis, acima de 0,50). Os pressupostos de normalidade, homoscedasticidade e linearidade das variáveis não foram satisfeitos. Considerou-se, contudo, que este resultado não impediria a realização da análise, pois Hair et al. (2005) observam que a violação destas suposições pode, apenas, reduzir a intensidade das correlações entre as variáveis. A exigência em relação às correlações, no entanto, foi cumprida, conforme mencionado.

No processo de análise fatorial é necessário realizar algumas escolhas (Hair et al., 2005; Pett et al., 2003). As decisões relatadas por Oliveira e Tamayo (2004), na extração fatorial do IPVO, foram empregadas no presente estudo para permitir melhor comparação com a solução extraída por estes autores: método de extração: análise de fatores comuns, opção PAF; método de rotação: oblíqua; e carga fatorial mínima das variáveis: 0,35. Oliveira e Tamayo (2004) não mencionam qual o tipo de rotação oblíqua utilizado. Deste modo, as soluções fatoriais resultantes das opções de rotação oblíqua Oblimin e Promax foram comparadas, em busca daquela com a estrutura mais simples, visto que a simplificação da estrutura é o objetivo da rotação (Pett et al., 2003). Outra decisão refere-se à comunalidade das variáveis. Hair et al. (2005) afirmam que cabe ao pesquisador definir o limite aceitável que, neste estudo, foi estabelecido em 0,50. Hair et al. (2005) também argumentam que a parcela mínima da variância total, em ciências sociais, deve ser de $60 \%$. Este percentual foi adotado. Finalmente, optou-se por estipular como 0,70 o valor mínimo de alpha de Cronbach para os fatores, seguindo recomendação de Hair et al. (2005).

O processo de análise com a aplicação das decisões descritas revelou que a estrutura resultante da rotação oblíqua Promax é a mais simples. Quatro fatores foram obtidos, nos quais permaneceram 30 variáveis e o total de variância explicada é de $67,9 \%$. Os coeficientes alpha dos quatro fatores situaram-se acima de 0,90, valor considerado excelente por Hair et al. (2006). A Tabela 3 apresenta as assertivas que compõem cada fator.

Tabela 3

Valores Organizacionais das Agências do Banco: Estrutura Fatorial

\begin{tabular}{lc}
\hline \multicolumn{1}{c}{ Fator 1: Respeito aos stakeholders } & Carga \\
\hline V16. Para esta agência, é importante que todas as pessoas sejam tratadas de maneira justa. É importante, & 0,910 \\
para ela, respeitar os direitos dos outros. & 0,849 \\
V38. Esta agência acredita que a pessoa deve ser honesta em qualquer situação. Dizer a verdade faz parte \\
dos princípios desta agência. \\
$\begin{array}{l}\text { V15. Esta agência acredita no valor da honestidade. Ela honra seus compromissos com pessoas e } \\
\text { organizações com as quais se relaciona. }\end{array}$ \\
$\begin{array}{l}\text { V3. Para esta agência, todas as pessoas devem ser tratadas com igualdade. Na visão dela, as pessoas } \\
\text { merecem oportunidades iguais. }\end{array}$ \\
$\begin{array}{l}\text { V21. Esta agência acha importante ser fiel a seus empregados e clientes. Ela cumpre seus compromissos } \\
\text { com eles. }\end{array}$ & 0,818 \\
\hline
\end{tabular}




\section{Tabela 3 (continuação)}

\begin{tabular}{lc}
\hline \multicolumn{1}{c}{ Fator 1: Respeito aos stakeholders } & Carga \\
\hline V44. Esta agência considera a lealdade importante. Ela é leal às agências e pessoas próximas dela. & 0,715 \\
V2. A sinceridade entre as pessoas é encorajada por esta agência. Ser verdadeiro com os outros é importante & 0,698 \\
para ela. & 0,662 \\
V34. Esta agência acredita que a cortesia é importante. Para ela, as boas maneiras fazem parte do \\
relacionamento entre os empregados e as agências. \\
$\begin{array}{l}\text { V5. É muito importante, para esta agência, ajudar seus empregados. Ela deseja cuidar do bem-estar deles. } \\
\text { V41. Nesta agência, as regras de convivência são consideradas importantes. Para ela, os empregados, } \\
\text { clientes e outras agências deveriam respeitá-las. }\end{array}$
\end{tabular}

\begin{tabular}{lc}
\hline \multicolumn{1}{c}{ Fator 2: Diversão para os empregados } & Carga \\
\hline $\begin{array}{l}\text { V9. Esta agência oferece oportunidades de diversão aos empregados. Ela acha importante que eles tenham } \\
\text { prazer no trabalho. }\end{array}$ & 0,979
\end{tabular}

V22. Para esta agência, é importante proporcionar lazer aos empregados. Ela considera que a diversão é $\quad 0,965$ uma parte importante da vida do empregado.

V48. Esta agência propõe atividades que dão prazer ao empregado. Na visão dela, é importante o empregado sentir-se satisfeito consigo mesmo.

V32. Esta agência preocupa-se com a qualidade de vida dos empregados. Ela realiza projetos sociais que contribuem para o bem-estar deles.

V14. Nesta agência, os empregados são premiados. A satisfação deles com a agência é uma meta importante.

\section{Fator 3: Atuação competente}

V37. Esta agência acha importante ser competitiva. Ela quer ganhar novos mercados.

V36. Para esta agência, planejar metas é essencial. Ela considera a realização das metas uma prova de sua $\quad 0,746$ competência.

V1. Esta agência estimula o empregado a enfrentar desafios. Para ela, os desafios tornam o trabalho do empregado mais interessante.

V23. Esta agência valoriza empregados curiosos. Ela gosta de empregados que procuram se informar a respeito do trabalho.

V24. Esta agência gosta de empregados que mostram suas habilidades. Ela procura desenvolver a competência desses empregados.

V29. Esta agência valoriza empregados que buscam realização no trabalho. Ela reconhece quando um empregado tem objetivos profissionais.

V13. Esta agência incentiva o sucesso profissional dos empregados. Ela os estimula a trabalharem de maneira competente.

V4. Esta agência valoriza a competência. Para ela, é importante que o empregado demonstre as habilidades e os conhecimentos que possui.

V8. Esta agência acha que é importante ser competente. Ela quer demonstrar o quanto é capaz.

V46. Esta agência incentiva o empregado a ser criativo. Ela estimula novas formas de atender os clientes.

V20. Nesta agência, é importante que os empregados conheçam bem o trabalho que fazem. Ela reconhece os empregados competentes

V30. Para esta agência, é importante ser criativa. Ela gosta de ser original.

\begin{tabular}{|c|c|}
\hline Fator 4: Prestígio & Carga \\
\hline V35. Esta agência tem influência na sociedade. Ela acha importante ser respeitada por todos. & 0,823 \\
\hline V25. Esta agência tem prestígio na sociedade. Ela acha importante ser admirada por todos. & 0,716 \\
\hline V33. Esta agência tem prestígio. Ela oferece produtos e serviços que são respeitados pelos clientes. & 0,675 \\
\hline
\end{tabular}


O fator 1 explica 54,8\% da variância total. Os itens com as cargas fatoriais mais elevadas fazem referência à importância, para uma agência, da justiça, honestidade, igualdade e lealdade nas relações entre a agência e clientes, empregados, outras agências, organizações e pessoas em geral. Um tema comum que aparenta expressar estas variáveis é o respeito; as assertivas citam vários grupos que possuem necessidades e interesses em relação a uma agência bancária. Optou-se, assim, por intitular este fator de: respeito aos stakeholders. O fator 2 possui variáveis que explicam 6,3\% da variância e foi nomeado diversão para os empregados. O conteúdo dos itens representa a preocupação da agência em proporcionar oportunidades de diversão, no ambiente ocupacional e fora dele, prazer e lazer aos funcionários. Os itens do fator 3, denominado atuação competente, demonstram o interesse da agência em ser competitiva, ganhar novos mercados e realizar as metas. A agência espera que os empregados desenvolvam suas competências, mostrem suas habilidades e vençam os desafios. Suas assertivas explicam 3,7\% da variância. O fator 4 explica 2,9\% da variância e reúne itens que expressam a importância, para uma agência, em ser admirada e respeitada pela sociedade e clientes. Prestígio foi o título escolhido para este fator.

Analisando-se a constituição do fator de respeito aos stakeholders, verifica-se que o mesmo reúne dez variáveis de três fatores obtidos por Oliveira e Tamayo (2004), assim distribuídas: sete itens de preocupação com a coletividade, dois de conformidade e um de bem-estar do empregado. Estes três fatores, conforme os autores citados (ver Tabela 1), possuem correspondência com quatro tipos motivacionais da teoria de valores pessoais de Schwartz (1992): benevolência e universalismo (conjuntamente), que se localizam no polo de autotranscendência; conformidade, que está posicionado no polo de conservação; e hedonismo, que está contido no polo de abertura à mudança ou autopromoção. A Tabela 4 resume as correspondências entre cada fator da estrutura de valores organizacionais das agências do Banco, os fatores encontrados por Oliveira e Tamayo (2004) e os tipos motivacionais e polos da teoria de valores pessoais de Schwartz (1992).

Da estrutura fatorial foram gerados os escores das variáveis independentes da presente pesquisa, calculando-se a média dos itens que compõem cada fator (Porto, 2005). Em seguida, foi obtida a hierarquia dos valores organizacionais das agências pesquisadas, em média: $\left(1^{\circ}\right)$ prestígio (média de $3,43$ e desvio-padrão de 0,70$) ;\left(2^{\circ}\right)$ respeito aos stakeholders (média de 3,42 e desvio-padrão de 0,66 ); $\left(3^{\circ}\right)$ atuação competente (média de 3,34 e desvio-padrão de 0,65 ); e $\left(4^{\circ}\right)$ diversão para os empregados (média de 2,42 e desvio-padrão de 0,84).

Tabela 4

\section{Correspondência entre as Estruturas Fatoriais dos Valores Organizacionais, Tipos Motivacionais e Polos Dimensionais}

\begin{tabular}{|c|c|c|c|}
\hline $\begin{array}{l}\text { Valores organizacionais das } \\
\text { agências do Banco }\end{array}$ & Valores organizacionais ${ }^{\mathrm{a}}$ & $\begin{array}{c}\text { Tipos motivacionais de } \\
\text { valores }^{\text {b }}\end{array}$ & Polos dimensionais $^{\mathrm{b}}$ \\
\hline \multirow{2}{*}{$\begin{array}{l}\text { Respeito aos stakeholders } \\
\text { (composto por } 10 \text { variáveis) }\end{array}$} & $\begin{array}{l}\text { Preocupação com a } \\
\text { coletividade }(7)^{\mathrm{c}}\end{array}$ & $\begin{array}{c}\text { Benevolência e } \\
\text { Universalismo (7) }\end{array}$ & $\begin{array}{c}\text { Autotranscendência (7) } \\
\text { Conservação (2) }\end{array}$ \\
\hline & $\begin{array}{c}\text { Conformidade (2) } \\
\text { Bem-estar do empregado (1) }\end{array}$ & $\begin{array}{l}\text { Conformidade (2) } \\
\text { Hedonismo (1) }\end{array}$ & $\begin{array}{l}\text { Abertura à mudança ou } \\
\text { autopromoção (1) }\end{array}$ \\
\hline $\begin{array}{l}\text { Diversão para os empregados } \\
\text { (composto por } 5 \text { variáveis) }\end{array}$ & Bem-estar do empregado (5) & Hedonismo (5) & $\begin{array}{l}\text { Abertura à mudança ou } \\
\text { autopromoção (5) }\end{array}$ \\
\hline $\begin{array}{l}\text { Atuação competente } \\
\text { (composto por } 12 \text { variáveis) }\end{array}$ & $\begin{array}{c}\text { Domínio (1) } \\
\text { Realização (5) } \\
\text { Autonomia (6) }\end{array}$ & $\begin{array}{c}\text { Poder (1) } \\
\text { Realização (5) } \\
\text { Autodeterminação e } \\
\text { Estimulação (6) }\end{array}$ & $\begin{array}{c}\text { Autopromoção (6) } \\
\text { Abertura à mudança (6) }\end{array}$ \\
\hline $\begin{array}{c}\text { Prestígio } \\
\text { (composto por } 3 \text { variáveis) }\end{array}$ & Prestígio (3) & Poder (3) & Autopromoção (3) \\
\hline
\end{tabular}

Nota. ${ }^{a}$ Fatores dos valores organizacionais obtidos por Oliveira e Tamayo (2004). ${ }^{b}$ Tipos motivacionais de valores e polos dimensionais da teoria de valores básicos ou pessoais de Schwartz (1992). ${ }^{c}$ Números em parênteses revelam a quantidade de variáveis da extração fatorial da presente pesquisa que pertencem aos fatores encontrados por Oliveira e Tamayo (2004) e que, por correspondência, representam os tipos motivacionais e polos da teoria de valores de Schwartz (1992). 
Para a verificação da hipótese do estudo, foram extraídos os coeficientes de correlação (expostos na Tabela 5) e o modelo de regressão linear múltipla. Na aplicação destas técnicas, Schwartz (2005b) recomenda que os valores sejam centralizados com o objetivo de corrigir as tendências dos pesquisados em concentrar as respostas em uma das extremidades da escala. $\mathrm{O}$ procedimento de centralização foi aplicado na presente pesquisa.

Tabela 5

Correlações entre as Variáveis Independentes e a Dependente

\begin{tabular}{ccccc}
\hline & Prestígio & $\begin{array}{c}\text { Respeito aos } \\
\text { stakeholders }\end{array}$ & Atuação competente & $\begin{array}{c}\text { Diversão para os } \\
\text { empregados }\end{array}$ \\
\hline Desempenho & $0,291^{* *}$ & $-0,170^{* *}$ & 0,087 & $-0,125^{*}$ \\
\hline
\end{tabular}

Nota. *valores significativos $p<.05$ (bi-caudal); **valores muito significativos $p<.01$ (bi-caudal).

$\mathrm{Na}$ análise de regressão múltipla, foi escolhido o método stepwise para extrair a equação, porque, de acordo com Abbad e Torres (2002), é a abordagem utilizada quando o pesquisador não dispõe de um modelo teórico sobre a sequência de entrada das variáveis preditoras. Os seguintes pressupostos estatísticos, exigidos antes da extração do modelo de regressão (Hair et al., 2005), foram verificados e atendidos na presente pesquisa: amostra com 50 vezes mais casos do que variáveis independentes (se adotado o procedimento stepwise); variáveis métricas; e normalidade, homoscedasticidade e linearidade das variáveis.

Dois modelos de regressão estatisticamente significativos mediante o teste da Razão F (24,904, com sig.: 0,000 e 15,217, com sig.: 0,000, respectivamente) foram gerados (Tabela 6). O primeiro explica $8,1 \%$ da variância com uma variável preditora. O segundo explica 9,5\% da variância com duas variáveis independentes e é mais preciso, visto que o erro padrão da estimativa (Hair et al., 2005) é menor. Destarte, o último modelo foi o escolhido. As suposições estatísticas exigidas após a estimação da equação de regressão, quais sejam: independência, normalidade e homoscedasticidade dos resíduos e linearidade do fenômeno, bem como a multicolinearidade das variáveis preditoras (Hair et al., 2005), foram verificadas e satisfeitas para as variáveis estatísticas dos dois modelos apresentados na Tabela 6.

Tabela 6

Regressão Múltipla Stepwise: Resultados dos Modelos

\begin{tabular}{|c|c|c|c|c|c|c|c|c|}
\hline Modelo & $\mathbf{R}$ & $\mathbf{R}^{2}$ & $R^{2} \mathbf{A j}$ & $\begin{array}{r}\text { Erro padrão } \\
\text { da estimativa }\end{array}$ & Variáveis & $\begin{array}{l}\text { Coef. de } \\
\text { regressão }\end{array}$ & $\begin{array}{l}\text { Coef. de regressão } \\
\text { padronizado (beta) }\end{array}$ & Sig. \\
\hline \multirow{3}{*}{1} & \multirow{2}{*}{0,291} & \multirow{2}{*}{0,085} & \multirow{2}{*}{0,081} & \multirow{2}{*}{9,34109} & Intercepto & 67,520 & N/A & 0,000 \\
\hline & & & & & Prestígio & 5,352 & 0,291 & 0,000 \\
\hline & & & & & Intercepto & 66,680 & N/A & 0,000 \\
\hline \multirow[t]{2}{*}{2} & 0,319 & 0,102 & 0,095 & 9,26994 & Prestígio & 5,713 & 0,311 & 0,000 \\
\hline & & & & & At_compet & 6,712 & 0,133 & 0,024 \\
\hline
\end{tabular}

Nota. N/A: não aplicável. At_compet: atuação competente.

A influência dos valores organizacionais das agências do Banco no desempenho pode ser interpretada a partir da teoria de valores pessoais de Schwartz (1992), pois a estrutura dos valores organizacionais é semelhante à dos valores pessoais, e o questionário utilizado para a mensuração do construto foi desenvolvido com base nesta teoria (Oliveira \& Tamayo, 2004).

$\mathrm{Na}$ equação de regressão, permaneceram duas variáveis preditoras positivamente associadas ao desempenho. O prestígio congrega assertivas pertencentes ao fator de mesmo nome obtido por 
Oliveira e Tamayo (2004), que o consideram representante de um tipo motivacional que, segundo a teoria de Schwartz (1992), pertence ao polo de autopromoção (ver Tabela 4). A atuação competente, por sua vez, reúne itens de três fatores que Oliveira e Tamayo (2004) julgam representantes de tipos motivacionais que se localizam no polo de abertura à mudança ou autopromoção (ver Tabela 4). No polo de abertura à mudança, estão valores que priorizam a novidade e a independência na ação e no pensamento e, no polo de autopromoção, valores que enfatizam o próprio sucesso. Estes dois polos não se contrapõem (Schwartz, 1992). A influência positiva conjunta dos dois fatores no desempenho pode ser justificada, portanto, pela ênfase que exprimem na busca de uma agência pelo seu sucesso.

Os polos de conservação e autotranscendência são opostos, respectivamente, aos de abertura à mudança e autopromoção (Schwartz, 1992). Por correspondência com a estrutura fatorial de Oliveira e Tamayo (2004), o fator de respeito aos stakeholders representa, principalmente, tipos motivacionais dos polos de autotranscendência e conservação e o fator de diversão para os empregados retrataria o tipo motivacional de hedonismo, que se posiciona no polo de autopromoção ou abertura à mudança (Schwartz, 1992) (ver Tabela 4). Este último fator, porém, aparenta expressar objetivos que caracterizam os tipos motivacionais do polo de autotranscendência. Esforçar-se para que os empregados tenham prazer e diversão no trabalho pode indicar uma preocupação da agência por interesses diferentes do alcance das metas e de resultados econômicos, que seriam primariamente relevantes. Schwartz (2005a) afirma que o universalismo e a benevolência, que compõem o polo de autotranscendência, compartilham uma ênfase na preocupação com os outros e a superação de interesses egoístas. Assim, poderia ser esperado que estes dois fatores apresentassem uma relação com o desempenho na direção inversa da obtida para o prestígio e a atuação competente. No modelo de regressão, eles não permaneceram como variáveis independentes, o que pode ser explicado pela multicolinearidade (Hair et al., 2005) com as variáveis preditoras já presentes na equação, que pode ter reduzido o poder preditivo adicional dos dois fatores. Os cálculos de correlação mostram, no entanto, que estão negativamente associados ao desempenho.

Schwartz (1992, 2005a) afirma que a estrutura de valores também pode ser organizada baseando-se em quem, principalmente, tem os seus interesses atendidos pela realização do valor. Os fatores associados positivamente ao desempenho, presentes no modelo de regressão (prestígio e atuação competente), representam tipos motivacionais (ver Tabela 4) que expressam interesses próprios (da agência, no caso). Esta também pode ser uma justificativa para a presença dos dois fatores na equação com o mesmo tipo de influência (positiva) na variável dependente. Já o fator de respeito aos stakeholders retrata (ver Tabela 4), e o de diversão para os empregados aparenta representar, tipos motivacionais que não atendem apenas a interesses próprios (da agência, no caso). Estes dois fatores estão negativamente correlacionados com o desempenho. Diante desta classificação dos valores organizacionais das agências do Banco, pode-se dizer que, quanto mais uma agência atribuir importância aos valores que enfatizam os seus interesses, maior será o seu desempenho e, ao valorizar mais a preocupação com os outros, menor será o seu percentual de realização das metas.

As interpretações dos resultados deste estudo, desenvolvidas a partir da teoria de Schwartz (1992, 2005a, 2006), se tornam mais compreensíveis ao analisar o índice de desempenho utilizado. O percentual de desempenho geral provém do modelo de avaliação dos resultados das agências do Banco, composto por 28 indicadores. Quase todos representam objetivos que são primariamente de interesse de uma agência, como margem financeira bruta e volume de empréstimos e financiamentos. Entre os diferentes grupos de stakeholders, estes objetivos pertenceriam aos investidores. Os fatores dos valores organizacionais das agências que permaneceram no modelo de regressão como influenciadores do desempenho (prestígio e atuação competente) expressam os polos de autopromoção e/ou abertura à mudança e tipos motivacionais da teoria de Schwartz (1992) que servem a interesses próprios. Assim, é justificável que uma maior importância concedida a estes valores por uma agência implique maior percentual de desempenho geral, considerando que quase todos os indicadores que compõem este índice expressam resultados primazes para uma agência.

Ao comparar os resultados da presente pesquisa com os obtidos por Voss et al. (2000), verificase que os fatores de prestígio e de atuação competente assemelham-se com a dimensão de realização da tipologia de valores identificada por estes autores. Esta dimensão expressa um interesse da 
organização de teatro em alcançar reconhecimento e exposição pública por produzir arte com um alto nível de excelência. O prestígio, para as agências do Banco, se refere à busca da admiração da sociedade e clientes, o que é compatível com a valorização do reconhecimento público pelas organizações de teatro. A atuação competente, por sua vez, inclui a preocupação da agência em ser competitiva e alcançar o sucesso, o que aparenta ser equivalente com a busca da excelência na produção teatral. Voss et al. (2000) identificaram que as organizações que mais valorizavam a realização conseguiam a maior quantidade de recursos financeiros, o que vai ao encontro dos resultados da presente pesquisa, já que o prestígio e a atuação competente influenciam positivamente o desempenho.

\section{Conclusão}

A partir dos resultados apresentados, o objetivo principal do estudo foi considerado atingido. Levando-se em consideração a extração do modelo de regressão, a hipótese foi parcialmente confirmada, pois os valores de respeito aos stakeholders e diversão para os empregados não permaneceram como variáveis preditoras. Estes fatores, no entanto, apresentaram correlações estatisticamente significativas com a variável dependente.

Os coeficientes de correlação e de regressão demonstraram a existência de relações de pequena intensidade entre os valores organizacionais das agências do Banco e o desempenho. É necessário mencionar, porém, que o desempenho das agências é uma variável complexa e sujeita ao impacto de inúmeros fatores. Além disto, esta variável foi mensurada de modo objetivo, utilizando-se registros factuais. O nível de associação entre o desempenho organizacional e uma variável preditora tende a ser maior, quando o desempenho é mensurado a partir da percepção e pela mesma fonte de avaliação da variável independente, visto que, neste caso, o pesquisado procuraria inferir o impacto da variável independente ao responder ao questionário (Becker \& Gerhart, 1996). As associações entre os valores organizacionais das agências e o desempenho destas unidades, portanto, podem ser consideradas relevantes, apesar de fracas estatisticamente.

Uma das limitações da pesquisa é a utilização de amostra não probabilística, formada por aproximadamente $12 \%$ das agências do Banco, o que não permite generalizar os achados para as demais agências desta instituição ou de outras. A quantidade média de respondentes por agência da amostra $(2,66)$ e os percentuais de empregados por unidade que participaram do estudo (entre $5 \%$ e $40 \%$ ), por sua vez, permitem questionar a representatividade da mensuração dos valores organizacionais das agências realizada. Este aspecto, no entanto, pode ter sido minimizado pelo tempo considerável de experiência nas agências de grande parte dos respondentes para conhecer os valores organizacionais: $72 \%$ dos participantes trabalhavam há pelo menos 2 anos na unidade avaliada.

São sugeridos novos estudos do efeito dos valores organizacionais no desempenho de agências bancárias e de outras organizações, para minimizar a carência de pesquisas que contemplam tais variáveis. Recomenda-se, ainda, a utilização de indicadores de desempenho organizacional que mensurem a satisfação dos interesses de outros grupos de stakeholders, além dos investidores, pois podem ser impactados pelos valores organizacionais de uma maneira diferente em comparação com a identificada na presente pesquisa.

Um aprimoramento do IPVO também é alvitrado. Cada questão deste questionário contém duas frases. No pré-teste realizado para adaptá-lo, um dos participantes considerou que as frases deveriam ser desmembradas, pois não necessariamente expressavam a mesma ideia. Guardani (2008) também submeteu o inventário a um pré-teste, no qual alguns respondentes mencionaram que a linguagem das assertivas era complexa e confusa. Hair et al. (2006) recomendam que as perguntas de um questionário sejam claras e que se evite a ambiguidade na sua formulação. Além destes aspectos, outro motivo que sugere o aperfeiçoamento do IPVO é a ausência, identificada por Oliveira e Tamayo (2004), de um fator que represente o tipo motivacional de segurança da teoria de Schwartz (1992). 
Por fim, considera-se que a presente pesquisa representa uma contribuição para o preenchimento de uma lacuna no conhecimento relativo aos valores organizacionais, mensurados com base em uma teoria de valores, que é a verificação empírica do seu impacto no desempenho organizacional, sendo que esta última variável foi medida de forma objetiva. Nota-se, também, a aplicabilidade do estudo na prática da gestão. Os valores organizacionais são elementos a serem considerados pelos gestores de agências bancárias na busca por melhor desempenho nestas unidades de negócio.

\section{Artigo recebido em 03.04.2011. Aprovado em 18.11.2011.}

\section{Referências}

Abbad, G., \& Torres, C. V. (2002). Regressão múltipla stepwise e hierárquica em psicologia organizacional: aplicações, problemas e soluções [Edição Especial]. Estudos de Psicologia, 7, 19-29. doi: 10.1590/S1413-294X2002000300004

Agle, B. R., \& Caldwell, C. B. (1999). Understanding research on values in business. Business and Society, 38(3), 326-387. doi: 10.1177/000765039903800305

Bartel, A. P. (2004). Human resource management and organizational performance: evidence from retail banking. Industrial and Labor Relations Review, 57(2), 181-203. doi: 10.2307/4126616

Becker, B., \& Gerhart, B. (1996). The impact of human resource management on organizational performance: progress and prospects. The Academy of Management Journal, 39(4), 779-801. doi: $10.2307 / 256712$

Cameron, K. (1981). Domains of organizational effectiveness in colleges and universities. The Academy of Management Journal, 24(1), 25-47. doi: 10.2307/255822

Cameron, K., \& Quinn, R. (1999). Diagnosing and changing organizational culture. Massachusetts: Addison-Wesley.

Canova, K. R., \& Porto, J. B. (2010). O impacto dos valores organizacionais no estresse ocupacional: um estudo com professores de ensino médio. Revista de Administração Mackenzie, 11(5), 4-31. doi: $10.1590 / \mathrm{S} 1678-69712010000500002$

Cavana, R. Y., Delahaye, B. L., \& Sekaran, U. (2001). Applied business research: qualitative and quantitative methods. Singapore: John Wiley \& Sons.

Combs, J. G., Crook, T. R., \& Shook, C. L. (2005). The dimensionality of organizational performance and its implications for strategic management research. In D. Ketchen Jr. \& D. D. Bergh (Eds.), Research methodology in strategy and management (Vol. 2, pp. 259-286). Amsterdam: Elsevier.

Cooper, D. R., \& Schindler, P. S. (2003). Métodos de pesquisa em Administração (7a ed.). Porto Alegre: Bookman.

Deal, T. E., \& Kennedy, A. A. (2000). Corporate cultures: the rites and rituals of corporate life (2a ed.). Massachusetts: Perseus Publishing.

Denison, D. R. (1997). Corporate culture and organizational effectiveness. New York: John Wiley \& Sons. 
Ferreira, M. C., Fernandes, H. A., \& Silva, A. P. E. (2009). Valores organizacionais: um balanço da produção nacional do período de 2000 a 2008 nas áreas de administração e psicologia. Revista de Administração Mackenzie, 10(3), 84-100. doi: 10.1590/S1678-69712009000300006

Gordon, G. G., \& DiTomaso, N. (1992). Predicting corporate performance from organizational culture. Journal of Management Studies, 29(6), 783-798. doi: 10.1111/j.14676486.1992.tb00689.x

Guardani, F. (2008). A relação entre os valores organizacionais, as práticas e a confiança dos clientes em organizações do setor de serviços (Tese de doutorado). Universidade Presbiteriana Mackenzie, São Paulo, SP, Brasil.

Hair, J. F., Jr., Anderson, R. E., Tatham, R. L., \& Black, W. C. (2005). Análise multivariada de dados (5a ed.). Porto Alegre: Bookman.

Hair, J. F., Jr., Babin, B., Money, A. H., \& Samouel, P. (2006). Fundamentos de métodos de pesquisa em administração. Porto Alegre: Bookman.

Hofstede, G. (2003). Culturas e organizações: compreender a nossa programação mental. Lisboa: Edições Sílabo.

Lytle, R. S. (1994). Service orientation, marketing orientation, and performance: an organizational culture perspective (Dissertação de doutorado). Arizona State University, Tempe, Arizona, Estados Unidos.

Mendes, A. M., \& Tamayo, A. (2001). Valores organizacionais e prazer-sofrimento no trabalho. Psico-USF, 6(1), 39-46. doi: 10.1590/S1413-82712001000100006

Neves, I. J. N., Jr., Garcia, S., \& Morgan, B. F. (2007). Definição de metas para avaliação de desempenho de agências bancárias. Revista de Administração Mackenzie, 8(4), 60-80.

Oliveira, A. F., \& Tamayo, A. (2004). Inventário de perfis de valores organizacionais. Revista de Administração da USP, 39(2), 129-140.

Pett, M. A., Lackey, N. R., \& Sullivan, J. J. (2003). Making sense of factor analysis: the use of factor analysis for instrument development in health care research. Thousand Oaks, CA: Sage Publications.

Porto, J. B. (2005). Mensuração de valores no Brasil. In A. Tamayo \& J. B. Porto (Orgs.), Valores e comportamento nas organizações (pp. 96-119). Petrópolis: Vozes.

Rohan, M. J. (2000). A rose by any name? The values construct. Personality and Social Psychology Review, 4(3), 255-277. doi: 10.1207/S15327957PSPR0403_4

Sampieri, R. H., Collado, C. F., \& Lucio, P. B. (2006). Metodologia de pesquisa (3a ed.). São Paulo: McGraw-Hill.

Schwartz, S. H. (1992). Universals in the content and structure of values: theoretical advances and empirical tests in 20 countries. Advances in Experimental Social Psychology, 25, 1-65. doi: $10.1016 /$ S0065-2601(08)60281-6

Schwartz, S. H. (1999). A theory of cultural values and some implications for work. Applied Psychology: an International Review, 48(1), 23-47. doi: 10.1111/j.1464-0597.1999.tb00047.x

Schwartz, S. H. (2005b). Chapter 4: measuring values. European Social Survey Edunet. Recuperado em 15 dezembro, 2010, de http://essedunet.nsd.uib.no/cms/topics/1/4/all.html 
Schwartz, S. H. (2005a). Valores humanos básicos: seu contexto e estrutura intercultural. In A. Tamayo \& J. B. Porto (Orgs.), Valores e comportamento nas organizações (pp. 21-55). Petrópolis: Vozes.

Schwartz, S. H. (2006). Há aspectos universais na estrutura e no conteúdo dos valores humanos? In M. Ros \& V. V. Gouveia (Orgs.), Psicologia social dos valores humanos: desenvolvimentos teóricos, metodológicos e aplicados (pp. 55-85). São Paulo: Senac.

Tamayo, A. (1998). Valores organizacionais: sua relação com satisfação no trabalho, cidadania organizacional e comprometimento afetivo. Revista de Administração da USP, 33(3), 56-63.

Tamayo, A. (2005a). Impacto dos valores pessoais e organizacionais sobre o comprometimento organizacional. In A. Tamayo \& J. B. Porto (Orgs.), Valores e comportamento nas organizações (pp. 160-186). Petrópolis: Vozes.

Tamayo, A. (2005b). Valores organizacionais e comprometimento afetivo. Revista de Administração Mackenzie, 6(3), 192-213.

Tamayo, A. (2007). Contribuições ao estudo dos valores pessoais, laborais e organizacionais [Edição Especial]. Psicologia: Teoria e Pesquisa, 23, 17-24. doi: 10.1590/S0102-37722007000500004

Tamayo, A., \& Borges, L. O. (2006). Valores do trabalho e das organizações. In M. Ros \& V. V. Gouveia (Orgs.), Psicologia social dos valores humanos: desenvolvimentos teóricos, metodológicos e aplicados (pp. 397-431). São Paulo: Senac.

Tamayo, A., \& Gondim, M. G. C. (1996). Escala de valores organizacionais. Revista de Administração da USP, 31(2), 62-72.

Tamayo, A., Mendes, A. M., \& Paz, M. G. T. (2000). Inventário de valores organizacionais. Estudos de Psicologia, 5(2), 289-315. doi: 10.1590/S1413-294X2000000200002

Venkatraman, N., \& Ramanujam, V. (1986). Measurement of business performance in strategy research: a comparison of approaches. Academy of Management Review, 11(4), 801-814. doi: 10.5465/AMR.1986.4283976

Venkatraman, N., \& Ramanujam, V. (1987). Measurement of business economic performance: an examination of method convergence. Journal of Management, 13(1), 109-122. doi: $10.1177 / 014920638701300109$

Voss, G. B., Cable, D. M., \& Voss, Z. G. (2000). Linking organizational values to relationships with external constituents: a study of nonprofit professional theatres. Organization Science, 11(3), 330-347. doi: 10.1287/orsc.11.3.330.12497 